\title{
Backstepping Control for Multi-Machine Web Winding System
}

\author{
Bousmaha Bouchiba ${ }^{\dagger}$, Abdeldjebar Hazzab*, Hachemi Glaoui*, Fellah Med-Karim**, \\ Ismaïl Khalil Bousserhane* and Pierre Sicard***
}

\begin{abstract}
This work treat the modeling and simulation of non-linear dynamic behavior of a web winding process during traction. We designate by a winding process any system applying the cycles of unwinding, transport, treatment, and winding to various flat products. This system knows several constraints, such as the thermal effects caused by the frictions, and the mechanical effects provoked by metal elongation, that generates dysfunctions due to the influence of the process conditions. Several controllers are considered, including Proportional-integral (PI) and Backstepping control. This paper presents the study of Backstepping controls strategy of the winding system. Our winding system is simulated in MATLAB SIMULINK environment, the results obtained illustrate the efficiency of the proposed control with no overshoot, and the rising time is improved with good disturbances rejections comparing with the classical control law.
\end{abstract}

Keywords: Winding system, Induction machine, Proportional-integral (PI), Backstepping control

\section{Introduction}

Many types of materials are manufactured or processed in the form of a sheet or a web (textile, paper, metal, etc.), which then couples the processing rolls and the associated motor drives. The drives are required to work in synchronism to ensure quality processing and rewinding of the product. Tension is a very important web manufacturing and process setting. If severe tension variations occur, rupture of the materiel during processing or degradation of product quality can occur, resulting into significant economic losses due to material loss and reduced production rate. Therefore, in order to minimize the potential for loss, the need arises to adequately control the tension within a predefined range in a moving web processing section. Henceforth, due to their importance in industry, tension control problems have drawn the attention of many researchers. One problem is the establishment of a proper mathematical model. In [1], a mathematical model of a web span is developed, but this model does not predict the tension transfer. This problem was addressed in [2] and [3], with the assumption that the strain in the web is very small. However, the form of the nonlinear and coupling terms in

$\uparrow \quad$ Corresponding Author: Laboratory of Control Analysis and Optimization of the Electro-Energetic Systems, Faculty of Sciences and Technology, BECHAR University B.P. 417 BECHAR, 08000 Algeria. (bouchiba_bousmaha@yahoo.fr)

* Laboratory of Control Analysis and Optimization of the ElectroEnergetic Systems, Faculty of Sciences and Technology, BECHAR University B.P. 417 BECHAR, 08000 Algeria.

(glaouih@yahoo.fr, a_hazzab@yahoo.fr,bou_isma@yahoo.fr)

** Laboratory of Intelligent Control and Electrical Power Systems (ICEPS) University of Sidi-Bel-Abbes.

*** Groupe de Recherche en Electronique Industrielle, École d'Ingénierie, Département de Génie électrique et Génie Informatique, Université du Québec à Trois-Rivières, Canada.

Received: January 17, 2010; Accepted: September 6, 2010 the model are not always convenient for controller design so that other model structures, with comparable precision, are desirable. Several control strategies have been suggested to maintain quality and reduce sensitivity to external disturbances, including centralized multivariable control schemes for steel mill applications [4], [5] and an $\mathrm{H} \infty$ control strategy to decouple web velocity and tension [3], [6]. Also, for tension regulation in a web transport system, [7] proposed a control method based on a unique active disturbance rejection control (ADRC) strategy, which actively compensates for dynamic changes in the system and unpredictable external disturbances,[7]. A Sensorless Backstepping technique combined with a field orientation scheme has been developed for the control of induction motor to achieve rotor angular speed and rotor flux amplitude tracking objectives. An accurate knowledge of the rotor speed is the key factor in obtaining a highperformance and high-efficiency induction motor drive in [8]. In this work the design of backstepping to control a winding system is proposed in order to improve the performances of the control system, which are coupled mechanically., and synthesis of the robust control and application to synchronize and to maintain a constant mechanical tension between the rollers of the system. The advantage of Backstepping control is its robustness and ability to handle the non-linear behaviour of the system.

The model of the winding system, and in particular the model of the mechanical coupling, are developed and presented in Section (2). Section (3) shows the direct fieldoriented control (FOC) of induction motor Section (4) shows the development of Backstepping technique control design. The Speed Control of Each induction machine by Backstepping controllers design is given in section (5). Simulation results using MATLAB SIMULINK of different studied cases is defined in Section (6). Finally, the conclusions are drawn in Section (7). 


\section{System Models}

In the mechanical part, the motor M1 carries out unreeling;, M3 drives the fabric by friction; and M5 is used to carry out winding;, each one of the motors M2 and M4 drives two rollers via gears "to grip" the band (Fig. 1). Each one of M2 and M4 could be replaced by two motors, which each one would drive a roller of the stages of pinching off. The elements of control of pressure between the rollers are not represented and not even considered in thestudy. The stage of pinching off can make it possible to isolate two zones and to create a buffer zone. [9], [10].

The objective of these systems is to maintain the tape speed constant and to control the tension in the band. The used motor is a three phase induction motor type (IM) supplied by an inverter voltage controlled with Pulse Modulation Width (PWM) techniques. A model based on circuit equivalent equations is generally sufficient in order to make control synthesis. The dynamic model of three-phase, Y-connected induction motor can be expressed in the $d-q$ synchronously rotating frame as [12]:

$$
\left\{\begin{aligned}
\frac{d i_{d s}}{d t}= & \frac{1}{\sigma \cdot L_{s}}\left(-\left(R_{s}+\left(\frac{L_{m}}{L_{r}}\right)^{2} \cdot R_{r}\right) \cdot i_{d s}+\sigma L_{s} \omega_{e} i_{q s}+\cdots\right. \\
& \left.\frac{L_{m} \cdot R_{r}}{L_{r}^{2}} \cdot \phi_{d r}+\frac{L_{m}}{L_{r}} \cdot \phi_{q r} \cdot \omega_{r}+V_{d s}\right) \\
\frac{d i_{q s}}{d t}= & \frac{1}{\sigma \cdot L_{s}}\left(-\sigma L_{s} \omega_{e} i_{d s}-\left(R_{s}+\left(\frac{L_{m}}{L_{r}}\right)^{2} \cdot R_{r}\right) \cdot i_{q s}-\cdots\right. \\
& \left.\frac{L_{m}}{L_{r}} \cdot \phi_{d r} \cdot \omega_{r}+\frac{L_{m} \cdot R_{r}}{L_{r}^{2}} \cdot \phi_{q r}+V_{q s}\right) \\
\frac{d \phi_{d r}}{d t}= & \frac{L_{m} \cdot R_{r}}{L_{r}} \cdot i_{d s}-\frac{R_{r}}{L_{r}} \cdot \phi_{d r}+\left(\omega_{e}-\omega_{r}\right) \cdot \phi_{q r} \\
\frac{d \phi_{q r}}{d t}= & \frac{L_{m} \cdot R_{r}}{L_{r}} \cdot i_{q s}-\left(\omega_{e}-\omega_{r}\right) \cdot \phi_{d r}-\frac{R_{r}}{L_{r}} \cdot \phi_{q r} \\
\frac{d \omega_{r}}{d t}= & \frac{P^{2} \cdot L_{m}}{L_{r} \cdot J} \cdot\left(i_{q s} \cdot \phi_{d r}-i_{d s} \cdot \phi_{q r}\right)-\frac{f_{c}}{J} \cdot \omega_{r}-\frac{P}{J} \cdot T_{l}
\end{aligned}\right.
$$
by

Where $\sigma$ is the coefficient of dispersion and is given

$$
\sigma=1-\frac{L_{m}^{2}}{L_{s} L_{r}}
$$

The tension model in web transport systems is based on Hooke's law, Coulomb's law, [3] mass conservation law, and the laws of motion for each rotating roll.

\subsection{Hooke's law}

The tension $\mathrm{T}$ of an elastic web is a function of the web strain $\varepsilon$, as expressed below:

$$
T=E S \varepsilon=E S \frac{L-L_{0}}{L_{0}}
$$

Where $\mathrm{E}$ is the Young modulus,; $\mathrm{S}$ is the web section,; L is the web length under stress; and $\mathrm{L}_{0}$ is the nominal web length (when no stress is applied).

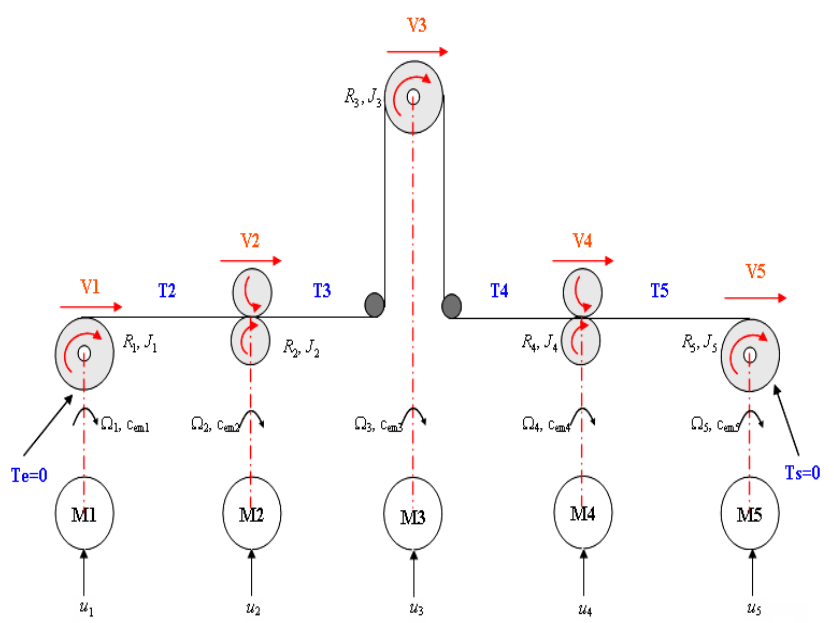

Fig. 1. Five motors web transport system.

\subsection{Coulomb's law}

The study of a web tension on a roll can be considered as a problem of friction between solids, (see [8] and [9]). On The roll, the web tension is constant on a sticking zone of arc length a and varies on a sliding zone of arc length $g$. The web tension between the first contact point of a roll and the first contact point of the following roll is given by:

$$
\begin{aligned}
& \varepsilon(x, t)=\varepsilon_{1}(t) \quad \text { if } \quad x \leq a \\
& \varepsilon(x, t)=\varepsilon_{1}(t) e^{\mu(x-a)} \quad \text { if } \quad a \leq x \leq a+g \\
& \varepsilon(x, t)=\varepsilon_{2}(t) \quad \text { if } \quad a+g \leq x \leq L_{t}
\end{aligned}
$$

Where $\mu$ is the friction coefficient, and $\mathrm{L}_{\mathrm{t}}=\mathrm{a}+\mathrm{g}+\mathrm{L}$. The tension change occurs on the sliding zone. The web velocity is equal to the roll velocity on the sticking zone.

\subsection{Mass conservation law}

Consider an element of web of length $L=L_{0}(1+\varepsilon)$ with a weight density $\rho$, under a unidirectional stress. The cross section is supposed to be constant. According to the mass conservation law, the mass of the web remains constant between the state without stress and the state with stress,

$$
\rho S L=\rho_{0} S L_{0} \Rightarrow \frac{\rho}{\rho_{0}}=\frac{1}{1+\varepsilon}
$$




\subsection{Tension model between two consecutive rolls.}

The equation of continuity, cf. [8], applied to the web gives

$$
\frac{\partial \rho}{\partial t}+\frac{\partial(\rho V)}{\partial x}
$$

By integrating on the variable $\mathrm{x}$ from 0 to $\mathrm{Lt}$ (cf. Fig. 2), taking into account (4), and using the fact that $\mathrm{a}+\mathrm{g}<<\mathrm{L}$, we obtain

$$
\frac{d}{d t}\left(\frac{L}{1+\varepsilon_{2}}\right)=\frac{V_{1}}{1+\varepsilon_{1}}-\frac{V_{2}}{1+\varepsilon_{2}} .
$$

Therefore:,

$$
-L \frac{d \varepsilon_{2}}{d t}=V_{1} \frac{\left(1+\varepsilon_{2}\right)^{2}}{1+\varepsilon_{1}}-V_{2}\left(1+\varepsilon_{2}\right)
$$

This equation can be simplified by using the approximation

$$
\varepsilon_{1}<<1 \text { and } \varepsilon_{2}<<1 \frac{\left(1+\varepsilon_{2}\right)^{2}}{1+\varepsilon_{1}} \approx\left(1-\varepsilon_{1}\right)\left(1+2 \varepsilon_{2}\right) \text {. }
$$

And using Hook's law, we get :

$$
\begin{aligned}
& L_{k-1} \frac{d T_{k}}{d t} \cong E S\left(V_{k}-V_{k-1}\right)+T_{k-1} V_{k-1}-T_{k}\left(2 V_{k-1}-V_{k}\right) . \\
& T_{l k}=R_{k}\left(T_{k+1}-T_{k}\right) \quad \text { Where } \quad \mathrm{k}=2,3,4,5 \text {. }
\end{aligned}
$$

where $\mathrm{L}_{\mathrm{k}-1}$ is the web length between roll $\mathrm{k}-1$ and roll $\mathrm{k}$; $\mathrm{T}_{\mathrm{k}}$ is the tension on the web between roll $\mathrm{k}-1$ and roll $\mathrm{k}$; $\mathrm{V}_{\mathrm{k}}$ is the linear velocity of the web on roll k; $\Omega_{\mathrm{k}}$ is the rotational speed of roll k;, $\mathrm{R}_{\mathrm{k}}$ is the radius of roll k;, $\mathrm{E}$ is the Young modulus, and $\mathrm{S}$ is the web section.

\subsection{Roll velocity calculation}

The law of motion can be obtained with a torque balance,:

$$
\frac{d\left(J_{k} \Omega_{k}\right)}{d t}=R_{k}\left(T_{k+1}-T_{k}\right)+C_{e m k}+C_{f}
$$

Where $\Omega_{k}=V_{k} / R_{k}$, is the rotational speed of roll $\mathrm{k}$; $C_{e m k}$ is the motor torque (if the roll is driven); and $C_{f}$ is the friction torque.

\subsection{State space representation}

The nonlinear state-space model is composed of (10) for the different web spans and of (11) for the different rolls.
Under the assumption that $\mathrm{J}_{\mathrm{k}} \mathrm{R}_{\mathrm{k}}(\mathrm{k}=2,3,4,5)$ is varying only slowly, which is the case for thin webs, $V_{k}$ can be chosen as a state variable in (11), leading to the following linear model:

$$
\begin{aligned}
& \left\{\begin{array}{l}
\frac{d T_{2}}{d t}=\frac{1}{L_{1}}\left(E S\left(V_{2}-V_{1}\right)-T_{2} V_{2}\right) . \\
\frac{d T_{3}}{d t}=\frac{1}{L_{2}}\left(E S\left(V_{3}-V_{2}\right)+T_{2} V_{2}-T_{3} V_{3}\right) . \\
\frac{d T_{4}}{d t}=\frac{1}{L_{3}}\left(E S\left(V_{4}-V_{3}\right)+T_{3} V_{3}-T_{4} V_{4}\right) . \\
\frac{d T_{5}}{d t}=\frac{1}{L_{4}}\left(E S\left(V_{5}-V_{4}\right)+T_{4} V_{4}-T_{5} V_{5}\right) . \\
\frac{d\left(J_{1} \Omega_{1}\right)}{d t}=R_{1} T_{2}+C_{e m 1}-f_{1}(t) \Omega_{1} . \\
\frac{d\left(J_{2} \Omega_{2}\right)}{d t}=R_{2}\left(T_{3}-T_{2}\right)+C_{e m 2}-f_{2}(t) \Omega_{2} . \\
\frac{d\left(J_{4} \Omega_{4}\right)}{d t}=R_{4}\left(T_{5}-T_{4}\right)+C_{e m 4}-f_{4}(t) \Omega_{4} . \\
\frac{d\left(J_{3} \Omega_{3}\right)}{d t}=R_{3}\left(T_{4}-T_{3}\right)+C_{e m 3}-f_{3}(t) \Omega_{3} . \\
\frac{d\left(J_{5} \Omega_{5}\right)}{d t}=R_{5}\left(-T_{5}\right)+C_{e m 5}-f_{5}(t) \Omega_{5} .
\end{array}\right. \text {. }
\end{aligned}
$$

Where

$$
\begin{aligned}
& X^{T}=\left[\begin{array}{lllllllll}
\left(T_{2}\right. & T_{3} & T_{4} & T_{5} & J_{1}(t) \Omega_{1} & J_{2} \Omega_{2} & J_{3} \Omega_{3} & J_{4} \Omega_{4} & \left.J_{5}(t) \Omega_{5}\right)
\end{array}\right] \\
& U=\left[\begin{array}{lllll}
u_{1} & u_{2} & u_{3} & u_{4} & u_{5}
\end{array}\right]
\end{aligned}
$$

\section{Vector Control}

The main objective of the vector control of induction motor is, to control independently the flux and the torque as a DC machines; this is done by using a $d-q$ rotating reference frame synchronously with the rotor flux space vector [10]. In ideally field-oriented control (FOC), the rotor flux linkage axis is forced to align with the $d$-axes, and it follows that [6], [7]

$$
\begin{gathered}
\phi_{q r}=\frac{d \phi_{q r}}{d t}=0 \\
\phi_{d r}=\phi_{r} .
\end{gathered}
$$

Applying the result of (13) and (14), namely the indirect field-oriented control (IFOC), the torque equation becomes analogous to the DC machine and can be described as follows:

$$
C_{e m}=\frac{P . L_{m}}{L_{r}} \phi_{d r} \cdot i_{q s}
$$


The decoupling control method with compensation is aims to obtain the inverter output voltages such that [11]:

$$
\begin{gathered}
V_{d s}^{*}=\left(K_{p}+K_{i} \frac{1}{s}\right)\left(i_{d s}^{*}-i_{d s}\right)-\omega_{e} \sigma L_{s} i_{q s}^{*} \\
V_{q s}^{*}=\left(K_{p}+K_{i} \frac{1}{s}\right)\left(i_{q s}^{*}-i_{q s}\right)+\omega_{e} \sigma L_{s} i_{d s}^{*}+\omega_{r} \frac{L_{m}}{L_{r}} \phi_{d r}
\end{gathered}
$$

According to the above analysis, the indirect fieldoriented control (IFOC) [10] of induction motor with current-regulated with PWM inverter control system can reasonably be presented by the block diagram shown in the Fig. 2.

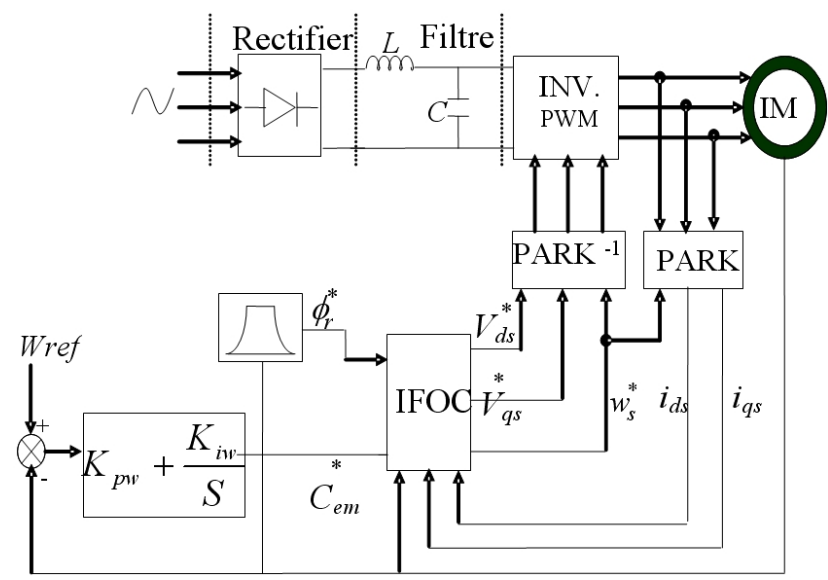

Fig. 2. Block diagram for each motor with PI control.

by the pole placement, the two complex poles are :

$$
s_{1,2}=\rho_{\omega} \cdot(1 \mp j)
$$

Where:

$$
\left\{\begin{array}{l}
K_{i \omega}=\frac{2 \cdot J \cdot \rho_{\omega}^{2}}{P} \\
K_{p \omega}=\frac{2 \cdot \rho_{\omega} \cdot J-f_{c}}{P}
\end{array}\right.
$$

\section{Backstepping Control Design}

In this section, we use the Backstepping algorithm to develop the speed control law of the induction motor This speed will converge to the reference value from a wide set of initial conditions.

\section{Step 1:}

Firstly we consider the tracking objective of the direct current $\left(\phi_{d r}\right)$. A tracking error $z_{1}=\phi_{d r}-\phi_{d r}^{*}$ is defined, and the derivative becomes:

$$
\dot{z}_{1}=\frac{R_{r}}{L_{r}} \cdot\left(L_{m} \cdot i_{d s}-\phi_{d r}\right)-\frac{d \phi_{d r}^{*}}{d t}
$$

To initiate Backstepping, we propose $i_{d s}$ as a first virtual control. If the function stability is proposed as:

$$
i_{d s}^{*}=\frac{\phi_{d r}}{L_{m}}+c_{1} \cdot \frac{\tau_{r}}{L_{m}} \cdot z_{1}+\frac{\tau_{r}}{L_{m}} \cdot \frac{d \phi_{d r}^{*}}{d t}
$$

We obtain:

$$
\dot{z}_{1}=c_{1} \cdot z_{1}+\frac{L_{m}}{\tau_{r}} \cdot\left(i_{d s}-i_{d s}^{*}\right)
$$

Due to the fact that $i_{d s}$ is not a control input, an error variable $z_{2}=i_{d s}-i_{d s}^{*}$ is defined, and we have the derivative as follows:

$$
\dot{z}_{1}=c_{1} \cdot z_{1}+\frac{L_{m}}{\tau_{r}} \cdot z_{2}
$$

\section{Step 2:}

The derivative of the error variable $z_{2}=i_{d s}-i_{d s}^{*}$ is: $\dot{z}_{2}=\frac{d i_{d s}}{d t}-\frac{i_{d s}^{*}}{d t}$

$\dot{z}_{2}=\frac{1}{\sigma \cdot L_{s}}\left(-\left(R_{s}+\left(\frac{L_{m}}{L_{r}}\right)^{2} \cdot R_{r}\right) \cdot i_{d s}+\sigma L_{s} \omega_{e} i_{q s}+\cdots\right.$
$\left.\frac{L_{m} \cdot R_{r}}{L_{r}^{2}} \cdot \phi_{d r}+\frac{L_{m}}{L_{r}} \cdot \phi_{q r} \cdot \omega_{r}+V_{d s}\right)-\frac{1}{\tau_{r} L_{m}} \cdot\left(L_{m} \cdot i_{d s}-\phi_{d r}\right)$

$-c_{1} \cdot\left(i_{d s}-\frac{\phi_{d r}}{L_{m}}-\frac{\tau_{r}}{L_{m}} \cdot \frac{d \phi_{d r}^{*}}{d t}\right)$

$-\frac{\tau_{r}}{L_{m}} \cdot \frac{d^{2} \phi_{d r}^{*}}{d t^{2}}$

We define:

$$
\phi_{1}=\frac{\left(\frac{L_{m}}{L_{r}}\right)^{2} \cdot R_{r}}{\sigma \cdot L_{s}} \quad \phi_{2}=w_{r} \cdot \frac{\frac{L_{m}^{2}}{L_{r}}}{\sigma \cdot L_{s}} \text { and } \phi^{2}=\phi_{1}^{2}+\phi_{2}^{2}
$$

The insertion of the control function in the dynamics of the variable error $z_{2}$ gives :

$$
\dot{z}_{2}=-c_{2} \cdot z_{2}-\frac{1}{\tau_{r}} z_{1}-d_{2} \cdot \phi^{2} \cdot z_{2}+\phi_{1} \cdot \frac{\phi_{d r}}{L_{m}}+\phi_{2} \cdot \frac{\phi_{q r}}{L_{m}}
$$


Step 3:

We now search to find the torque tracking error. The tracking error is for $\phi_{d r} \neq 0$, which is defined as:

$$
z_{3}=i_{q s}-\frac{C_{e m}^{*}}{\left(P \cdot \frac{L_{m}}{L_{r}} \cdot \phi_{d r}\right)}
$$

Then, its derivative is:

$$
\begin{aligned}
\dot{z}_{3} & =\frac{1}{\sigma \cdot L_{s}} \cdot V_{q s}-\frac{1}{\sigma \cdot L_{s}} \cdot\left(R_{s} \cdot i_{s q}+w_{e} \cdot \sigma \cdot L_{s} \cdot i_{d s}+\left(\frac{L_{m}}{L_{r}}\right)^{2} \cdot R_{r} \cdot i_{q s}\right. \\
+ & \left.w_{r} \cdot(1-\sigma) \cdot L_{s} \cdot \frac{\hat{\phi}_{d r}}{L_{m}}\right)-\frac{\left(\frac{L_{m}}{L_{r}}\right)^{2} \cdot R_{r}}{\sigma \cdot L_{s}} \cdot \frac{\phi_{q r}}{L_{m}}+w_{r} \cdot \frac{\frac{L_{m}^{2}}{L_{r}}}{\sigma \cdot L_{s}} \cdot \frac{\phi_{d r}}{L_{m}} \\
& +\frac{L_{r} \cdot C_{e m}^{*}}{P \cdot \phi_{d r}^{2}} \cdot \frac{1}{\tau_{r}} \cdot\left(i_{d s}-\frac{\hat{\phi}_{d r}}{L_{m}}\right)-\frac{L_{r}}{P \cdot L_{m} \cdot \hat{\phi}_{d r}} \cdot \frac{d C_{e m}^{*}}{d t}
\end{aligned}
$$

Viewing $\varphi_{d r}$ and $\varphi_{q r}$ as unknown disturbances, we apply nonlinear damping [13] to design the control function:

$$
\begin{aligned}
& \frac{1}{\sigma \cdot L_{s}} \cdot V_{q s}=\frac{1}{\sigma \cdot L_{s}} \cdot\left(R_{s} \cdot i_{q s}-w_{e} \cdot \sigma \cdot L_{s} \cdot i_{q s}+\left(\frac{L_{m}}{L_{r}}\right)^{2} \cdot R_{r} \cdot i_{q s}\right. \\
& \left.\quad+w_{r} \cdot(1-\sigma) \cdot L_{s} \cdot \frac{\phi_{d r}}{L_{m}}\right)-\frac{2 \cdot L_{r} \cdot C_{e m}^{*}}{3 \cdot P \cdot \phi_{d r}} \cdot \frac{1}{T_{r}} \cdot\left(i_{d s}-\frac{\phi_{d r}}{L_{m}}\right) \\
& +\frac{L_{r}}{P \cdot L_{m} \cdot \phi_{d r}} \cdot \frac{d C_{e m}^{*}}{d t} \\
& -c_{3} \cdot z_{3}-d_{3} \cdot\left\{\left(\frac{\left(\frac{L_{m}}{L_{r}}\right)^{2} \cdot R_{r}}{\sigma \cdot L_{s}}\right)^{2}+\left(w_{r} \cdot \frac{(1-\sigma)}{\sigma}\right)^{2}\right\} \cdot z_{3}
\end{aligned}
$$

The insertion of the control function in the dynamics of the variable error $z_{3}$ gives:

$$
\dot{z}_{3}=-c_{3} \cdot z_{3}-d_{3} \cdot \phi^{2} \cdot z_{3}+\phi_{1} \cdot \frac{\phi_{q r}}{L_{m}}+\phi_{2} \cdot \frac{\phi_{d r}}{L_{m}}
$$

The combined controller is shown in Fig. 3, where we have

$$
\left\{\begin{array}{l}
V_{d s, f f}=R_{s} \cdot i_{d s}-\omega_{s} \cdot \sigma \cdot L_{s} \cdot i_{q s}+\left(\frac{L_{m}}{L_{r}}\right)^{2} \cdot R_{r} \cdot\left(i_{d s}-\frac{\phi_{d r}}{L_{m}}\right) \\
V_{q s, f f}=R_{s} \cdot i_{s q}-\omega_{s} \cdot \sigma \cdot L_{s} \cdot i_{q s}+\left(\frac{L_{m}}{L_{r}}\right)^{2} \cdot R_{r} \cdot i_{s q}+ \\
\omega_{r} \cdot(1-\sigma) \cdot L_{s} \cdot \frac{\phi_{d r}}{L_{m}} \\
V_{d s, n l}=\sigma \cdot L_{s} \cdot\left\{\left(\frac{1}{\tau_{r}}-c_{1}\right) \cdot\left(i_{d s}-\frac{\phi_{d r}}{L_{m}}\right)-\frac{1}{L_{m} \cdot \tau_{r}}\left(\phi_{d r}-\phi_{d r}^{*}\right)\right\} \\
V_{q s, n l}=-\frac{L_{m}^{2} \cdot C_{e m}^{*}}{P \cdot(1-\sigma) \cdot L_{s} \cdot \phi_{d r}^{2}} \cdot \frac{\sigma \cdot L_{s}}{\tau_{r}} \cdot\left(i_{d s}-\frac{\phi_{d r}}{L_{m}}\right)
\end{array}\right.
$$
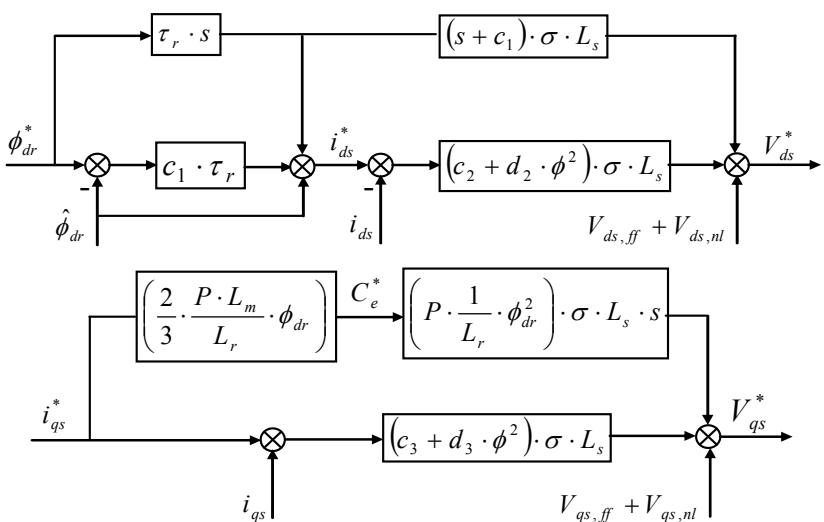

Fig. 3. Indirect field-oriented control (IFOC) of induction motor using Backstepping technique.

\section{Speed Control of Each IM Using Backstepping}

To control the speed of the IM, We consider that $i_{q s}^{*}$ is the control law,; so tracking error is defined as:

$$
z_{0}=\omega_{r}^{*}-\omega_{r}
$$

So, its derivate is given as:

$$
\begin{gathered}
\dot{z}_{0}=\dot{\omega}_{r}^{*}-\dot{\omega}_{r} \\
\dot{z}_{0}=\dot{\omega}_{r}^{*}-\left[\frac{P^{2} \cdot L_{m}}{L_{r} \cdot J} \cdot i_{q s} \cdot \phi_{d r}-\frac{f_{c}}{J} \cdot \omega_{r}-\frac{P}{J} \cdot T_{l}\right]
\end{gathered}
$$

The control law obtained is:

$$
\begin{gathered}
i_{q s}^{*}=\frac{L_{r} \cdot f_{c}}{P^{2} \cdot L_{m} \cdot \phi_{d r}} \cdot \omega_{m}+c_{0} \frac{L_{r} \cdot J}{P^{2} \cdot L_{m} \cdot \phi_{d r}} z_{0}+\frac{L_{r}}{P \cdot L_{m}} \cdot C_{r} \\
C_{e m}^{*}=P \cdot \frac{L_{m}}{L_{r}} \cdot \phi_{d r} \cdot i_{q s}^{*}
\end{gathered}
$$

The Fig. 4 shows the backstepping control strategy scheme for each induction motor. 


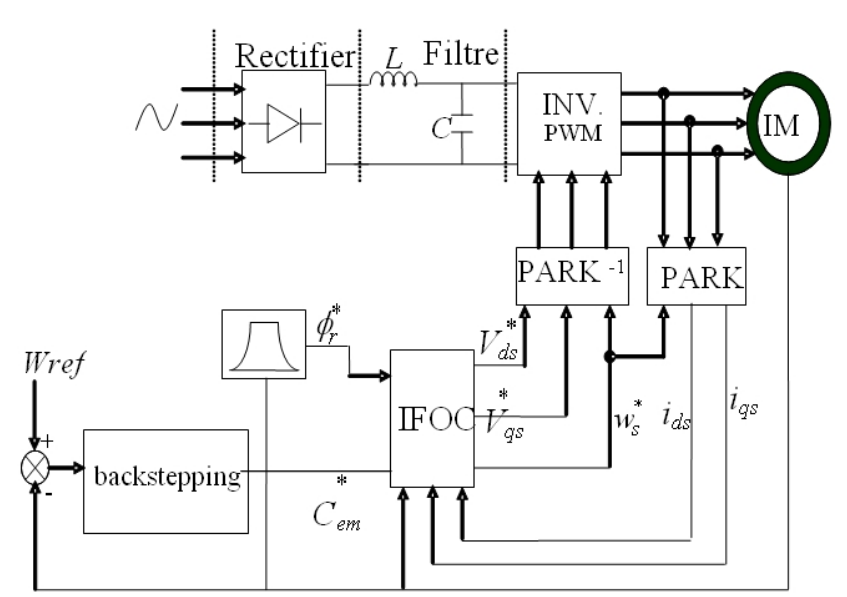

Fig. 4. Block diagram for each motor with backstepping control.

\section{Simulation Results}

The winding system we modeled is simulated using MATLAB/SIMULINK software and the simulation is carried out on $10 \mathrm{~s}$.

To evaluate system performance, we carried out numerical simulations under the following conditions:

- Start with the linear velocity of the web of $5 \mathrm{~m} / \mathrm{s}$.

- The motor M1 has the role of unwinder a radius R1 (R1 $=2.25 \mathrm{~m}$ ).

- The motors M2, M3, M4 are pinching the tape.

- The motor M5 has the role of winding a roll of radius R5.

Figs. (5-7), shows that the effect of the disturbance is neglected in the case of the Backstepping controller. It appears clearly that the classical control with PI controller is easy to apply. However, the control with Backstepping offers better performance in the overshoot control.

The comparison between the two controllers PI controller and Backstepping control is achieved by comparison of the control performances: it has been made by the comparison of the average speeds of the five motors $\mathrm{V}_{\text {avg }}$, for each controller; this average is expressed by the equation (35).

$$
V_{a v g}=\frac{1}{n} \sum_{i=1}^{n} V_{i}
$$

As shown in Figs. (5-7). An improvement of the linear speed is registered, and has follows the reference speed for both PI controller and Backstepping control, but in case of PI controller, the overshoot in linear speed of unwinder is $25 \%$. Figs. (5-7) show that with the Backstepping control, the system follows the reference speed after $0.5 \mathrm{~s}$ in all motors, however, in the PI controller the system follows after $2 \mathrm{~s}$.

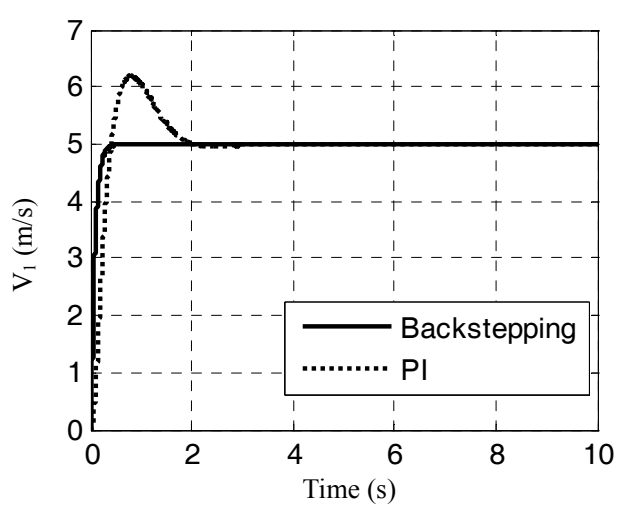

Fig. 5. The linear speed of unwinder M1.

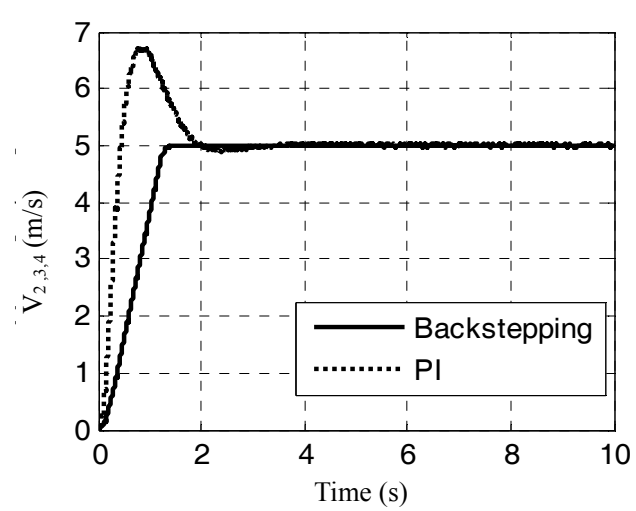

Fig. 6. The linear speed of motors M2, M3, and M4.

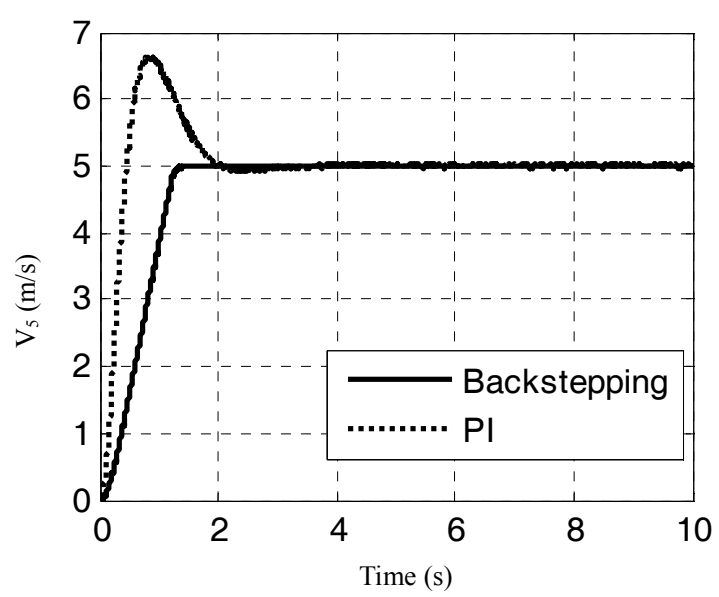

Fig. 7. The linear speed of winder M5.

Fig. 8 Shows the comparison between the PI controller, and the backstepping controller. After this comparison we can judge that the Backstepping controller presents a clear improvement to the level of the performances of control, compared to the PI controller. The synchronism between the five motors is improved with Backstepping control compared to PI controller. 


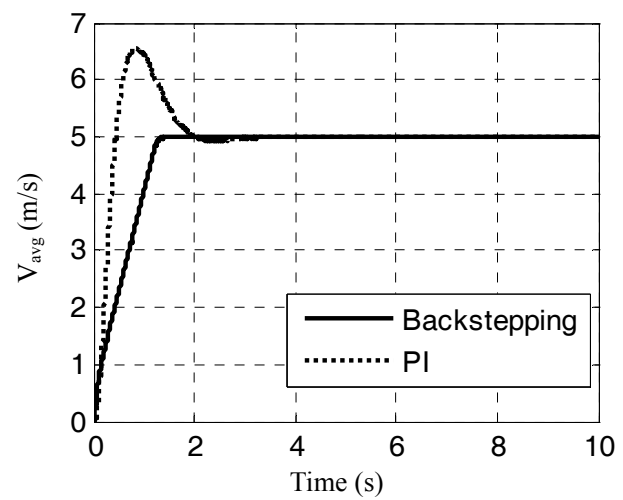

Fig. 8. Comparison between the PI and Backstepping with average speeds of five motors.

\section{Conclusion}

The objective of this paper consists in developing a model of a winding system constituted of five motors that are coupled mechanically by a web whose tension is adjustable.and to develop the methods of analysis and synthesis and their application to synchronize.

The simulations results show the efficiency of the Backstepping control technique. The strategy of Backstepping Control brings good performances, and it is more efficient than the classical PI controller.

\section{References}

[1] D. P. Cambell, Process Dynamics, Wiley, 1958, pp. 113-156.

[2] G. Brandenburg, "New Mathematical Model For Web Tension and Register Error,» Proceedings of the 3rd IFAC Conference on Instrumentation and Automation in The Paper, Rubber and Plastics, Vol. 1, May 1976, pp.411-438.

[3] H. Koç, D. Knittel, M de Mathelin and G. Abba, "Modeling and Robust Control of Winding Systems for Elastic Webs," IEEE Trans. Contr. Syst. Technol., Vol. 10, March 2002, pp.197-208.

[4] J.E. Geddes and M. Postlethwaite, "Improvements in Product Quality in Tandem Cold Rolling Using Robust Multivariable Control," IEEE Trans. Contr. System. Technology. Vol. 6, March 1998, pp.257-267.

[5] S.H. Jeon, and al., "Decoupling Control of Bridle Rolls for Steel Mill Drive System» IEEE Trans. Ind. Application., Vol. 35, January/February 1999, pp. 119-125.

[6] D. Knittel, and al., "Tension Control for Winding Systems With Two-Degrees of Freedom Ho Controllers," IEEE Trans. Ind. Applicat. Syst., Vol. 39, January/February 2003, pp.113-120.

[7] B.T. Boulter, Y. Hou, Z. Gao and F. Jiang., "Active Disturbance Rejection Control for Web Tension Regulation and Control," IEEE Conference on Deci- sion and Control, Orlando, USA, December 2001, pp. 4974-4979.

[8] F. Mehazzem, A. Reama, H. Benalla“ Sensorless Nonlinear Adaptive Backstepping Control of Induction Motor" ICGST-ACSE Journal, ISSN 1687-4811, Volume 8, Issue III, January 2009.

[9] Lin, F. J., and Lee, C. C., 'Adaptive backstepping control for linear induction motor drive to track period refernces', IEE Proc. Electr. Power Appl., 2000,147, (6), pp 449-458.

[10] Yaolong, T., Chang, J., Hualin, T., 'Adaptive Backstepping Control and Friction Compensation for AC Servo with Inertia and Load Uncerainties', IEEE Trans. On Ind. Elect., Vol 50, No. 5, 2003. pp 145155.

[11] G.Brandenburg, „Ein mathematisches Modell fur eine durchlaufende elastische Stoffbahn in einem System angetriebener, umschlungener, Walzen, “ Regelungstechik und Prozess-Datenverarbeitung, Vol. 3, 69-162, 1973.

[12] Benaskeur, A.R.: 'Aspects de l'application du backstepping adaptatif à la commande décentralisée des systèmes non-linéaires'. $\mathrm{PhD}$ thesis, Department of Electrical and Computer Engineering, Universite Laval, Quebec City, Canada, 2000;

Bouchiba Bousmaha was born in 1977 at Bechar-Algeria, he's received the electrical engineering diploma from $\mathrm{Be}-$ char University,-Algeria in 1999, and the Master degree from the University Alexandria Egypt in 2006. Currently, he is an assistant professor at Bechar University. He's currently preparing his Ph.d. degree in multi machine system control.

Hazzab Abdeldjebar received the state engineer degree in electrical engineering in 1995 from the University of Sciences and Technology of Oran (USTO), Algeria the M.Sc. degree from the Electrical Engineering Institute of the USTO in 1999, and the Ph.D. degree from the Electrical Engineering Institute of the USTO in 2006. He is currently professor of electrical engineering at University of Bechar, Bechar, Algeria, where he is Director of the Research Laboratory of Control Analysis and Optimization of the Electro-Energetic Systems.

His research interests include power electronics, electric drives control, and artificial intelligence and their applications.

Hachemi Glaoui received the B.Sc. degree in electrical engineering diploma from Bechar University-, Algeria in 2001, and the Master degree from Bechar UniversityAlgeria in 2008, currently preparing his Ph.d degree in multi machine system control.

His research interests include power electronics, electric drives control, and artificial intelligence and their applications. 
Ismail Khalil Bousserhane received the B.Sc. degree in electrical engineering from the Electrical Engineering Institute of the University Center of Bechar in 2000, the M.Sc. degree in electrical engineering from the University of Sciences and Technology of Oran (USTO), Algeria, in 2003 and the Ph.D. degree from the Electrical Engineering Institute of USTO in 2008, He is currently professor of electrical engineering at University of Béchar, Béchar, Algeria.

His research interests include modern control techniques and their application to electric drives control.
Pierre Sicard received the Master degree in industrial electronics from the University of Quebec in TroisRivieres, Trois-Rivieres, Canada, in 1990, and a Ph.D. degree in electrical engineering from Rensselaer Polytechnic Institute, Troy NY, USA in 1993. He is professor in electrical and computer engineering at University of Quebec in Trois-Rivieres, where he is director of the Research group on industrial electronics.

His research interests include the system control of multi drive and power electronic system. 